\title{
Amplification, Sequencing and Cloning of Iranian Native Bacillus subtilis Alpha-amylase Gene in Saccharomyces cerevisiae
}

\author{
Fahimeh Afzal-Javan ${ }^{1,2}$, Mohsen Mobini-Dehkordi ${ }^{1,2,}$ \\ ${ }^{1}$ Department of Genetics, Faculty of Science, University of Shahrekord, Shahrekord, IR Iran \\ 2 Research Institute of Biotechnology, University of Shahrekord, Shahrekord, IR Iran \\ ${ }^{*}$ Corresponding author: Mohsen Mobini-Dehkordi, Department of Genetics, Faculty of Science, University of Shahrekord, Shahrekord, IR Iran. Tel/Fax. +98-3814424419, E-mail: mmo- \\ binid@gmail.com.
}

Received: July 22, 2012; Revised: December 8, 2012; Accepted: December 22, 2012

\begin{abstract}
Background: Alpha-amylases are digestive enzymes which hydrolyze starch glycosidic bonds to glucose, maltose, maltotriose and dextrin which have diverse applications in a wide range of industries such as food, textile, paper, detergents representing approximately $30 \%$ of the world enzyme production.

Objectives: In this study, the gene encoding the alpha-amylase enzyme of native isolated Bacillus subtilis was amplified with specific primers containing of NotI and AscI restriction sites by PCR and then sequenced. Purified PCR product and shuttle episomal vector p316TDH3 were cut by restriction enzymes and cloned into Escherichia coli and yeast hosts.

Materials and Methods: The haploid auxotroph (ura3-) strain of Saccharomyces cerevisiae and p316TDH3 were used as the host and vector for cloning and expression of the alpha amylase gene, respectively. In native Bacillus sp. the amyE gene without signal sequence was amplified with specific primers that introduced AscI and NotI restriction sites. After constructing the recombinant plasmid, it was transformed into E. coli competent cells. Then, colonies selection and confirmation were performed and the extracted plasmid was introduced to competent yeast cells using carrier sperm DNA. Recombinant yeast cells could grow on minimal media and produce extracellular enzyme.

Results: The presence of alpha-amylase gene in recombinant bacteria was certificated by colony-PCR method. After extraction of recombinant vector from $E$. coli, the competent $S$. cerevisiae cells were transformed using polyethylene glycol and carrier sperm DNA. The recombinant yeast strains were screened by URA3 auxotrophic marker and analyzed for alpha-amylase gene existence. In the other hand, the amylase gene length of native B. subtilis was 1887 base pairs (bp) with an approximately $93.65 \%$ similarity with standard bacterial strain . Conclusions: Based on this similarity and our bioinformatics evaluations, this mentioned alpha-amylase gene can be expressed in $S$. cerevisiae as extracellular enzyme.
\end{abstract}

Keywords: Industrial Enzyme; Cloning; Alpha-amylase

\section{Background}

Amylases constitute a class of industrial enzymes, representing approximately $30 \%$ of the world enzyme production (1). They have diverse applications in a variety of industries such as food, fermentation, textile, paper, detergent and sugar industries. It can be used in field related to biotechnology such as: environmental pollutant remediation, conversion of starch to desired substrates by many microorganisms, infiltration of waste contains starch and production biochemical material with the help of starch substrate. With the advent of new frontiers in biotechnology, the spectrum of amylase application has expanded into many other fields, such as clinical studies, medicine and analytical chemistry. Interestingly, the first enzyme produced industrially was an fungal source amylase in 1894, which was used as a pharmaceu- tical drug for the treatment of digestive disorders (2). $\mathrm{Al}$ though amylases can be derived from several sources, including plants, animals and microorganisms, microbial enzymes generally meet industrial demands $(3,4)$.

The major advantage of using microorganisms for the production of amylases is the economical mass production capacity and the fact that microbes are easy to manipulate to produce enzymes with desired characteristics (5). Fungal sources are confined to terrestrial isolates, mostly to Aspergillus species and to only one species of Penicillium, P. brunneum (6). The microbial amylases have almost completely replaced chemical hydrolysis of starch in starch processing industry (7). It is estimated that Bacillus sp. enzymes compromised about $50 \%$ of the total global enzyme market (8). Bacillus subtilis, B. stearothermophilus, B. licheniformis and B. amyloliquifaciens are known to be good producers of alpha-amylase $(9,10)$.

Implication for health policy/practice/research/medical education:

This research project has a good innovation because of cloning alpha-amylase gene of a native Iranian Bacillus sp. into Saccharomyces host for the first time. One of the results of this project is design of a new recombinant strain of yeast that has much importance for biotechnology.

Copyright @ 2013, Ahvaz JundishapurUniversity of Medical Sciences; Published by Kowsar Corp. This is an open-access article distributed under the terms of the Creative Commons Attribution License, which permits unrestricted use, distribution, and reproduction in any medium, provided the original work is properly cited. 
Most important genetic engineering proceed to introduce recombinant alpha-amylase can signify transmit of alpha-amylase gene from bacillus species to other microbial host (11). Some recombinant strain had represented to enhance production of enzyme because of high expression of gene (12). Also gene transmission has done from bacterial source into yeast Saccharomyces cerevisiae (11). The bakers' yeast, S. cerevisiae, is one of the most important microorganisms bioindustries, and is one of the best model organisms for basic biological research. This yeast is the first eukaryote that its genome is entirely sequenced in 1996 (13). Based on defined information that established many decades ago $S$. cerevisiae autonomously replicating plasmid, the cell transformation system, and the ability to rapidly form colonies on simple defined media ensured that it remained at the forefront of developments during the recombinant DNA revolution.

The DNA sequence of $S$. cerevisiae was just the starting point for large-scale molecular analysis of eukaryotic cells (14). Unlike most other microorganisms, yeast strains have both stable haploid and diploid states. Thus, recessive mutations can be easily isolated and showed in haploid strains, and the complementation tests can be carried out in diploid strains. The development of DNA transformation has made yeast a proper candidate for gene cloning and genetic engineering techniques. Structural genes corresponding to virtually any genetic traits can be identified by complementation from plasmid libraries. Plasmids can be introduced into yeast cells either as the episomal replicating cassettes or by integration into the yeast genome (15). On the other hand, gene transmission has been done from fungal source into the prokaryote and eukaryote hosts $(16,17)$.

Amylases are one of the most important industrial enzymes that have a wide variety of applications in biotechnology. Alpha amylases (E.C. 3.2.1.1.) are starch-degrading enzymes that catalyze the hydrolysis of internal $\alpha-1,4-0$ glycosidic bonds in polysaccharides with the retention of $\alpha$-anomeric configuration in low molecular weight products, such glucose, maltose and maltotriose units (18). Most of the a-amylases are metallo enzymes, which require calcium ions (Ca2+) for their activity, structural integrity and stability. They belong to the family 13 (GH-13) of the glycoside hydrolase group of enzymes. These enzymes possess an $8(\alpha / \beta)$ or TIM barrel structure containing the catalytic site residues and consisted of four highly conserved regions in their primary sugar syrups, to produce cyclodextrins for the pharmaceutical industry (19). The properties of $\alpha$-amylases such as thermo-stability and $\mathrm{pH}$ profile should match the application $(20,21)$.

\section{Objectives}

The present study describes the amplification, sequencing and cloning of the alpha-amylase gene from Iranian native B. subtilis source in S. cerevisiae host.

\section{Materials and Methods}

\subsection{Strains and Culture Condition}

The bacterial strains used in this study were native $B$. subtilis and Escherichia coli DH5 $\alpha$. The haploid auxotroph (ura3-) strain of S. cerevisiae and p316TDH3 were used as the host and vector for cloning and expression of the alpha amylase gene, respectively. Chemically competent $E$. coli $\mathrm{DH} 5 \alpha$ cells were used for plasmid transformation (18). The competent yeast cells were preparedusing lithium acetate and heat shock protocol (14). The Bacilli isolated from soil were grown in a Tryptic (Merck, Germany)Soy Agar (TSA) medium. B. subtilis was grown in a LuriaBertani (Merck, Germany)(LB) medium with $1 \%$ soluble starch at $37^{\circ} \mathrm{C}$. Cultures of S. cerevisiae were grown at $30 \mathrm{C}$ and in Yeast Extract Peptone Dextrose (YPD) medium (Difco, Europe union). The YPD medium contained $1 \%$ yeast extract, $1 \%$ peptone, $2 \%$ glucose and $1.5 \%$ agar. Cultured recombinant $S$. cerevisiae were grown at $30^{\circ} \mathrm{C}$ on a minimal medium. The minimal medium contained $0.17 \%$ Yeast $\mathrm{Ni}$ trogen base (YNB), $0.5 \%$ ammonium sulphate, $2 \%$ glucose and $2 \%$ agar was used for selection of recombinant yeast cells that containing genetic construct.

\subsection{Isolation of Bacilli From Soil}

Soil samples were collected from five different regions. The soil was processed by removing all large particles and plant materials such as leaves. Each soil sample (5 g) was suspended in $5 \mathrm{~mL}$ of sterile distilled water in a sterile universal bottle. Soil suspensions were vortexed and placed in a water bath with temperature adjusted to $85^{\circ} \mathrm{C}$. Heat treatment of the soil suspensions was performed at $85^{\circ} \mathrm{C}$ for 15 minutes. After heat treatment, heat-treated soil suspensions were incubated at room temperature for 2 hours and then plated on TSA medium for isolation of single colonies. Plates were incubated at $37^{\circ} \mathrm{C}$ for 16 hours. In order to identify Bacilli producing alpha amylase, extracted bacilli were grown in starch medium.

\subsection{Bioinformatics Analysis}

The amyE gene sequences obtained from NCBI, EBI and Ensemble sites were compared by CLC Main Workbench 5-6-1- Limited Mode software. The oligonucleotide primers were designed based on the nucleotide sequences of $B$. subtilis gene in order to obtain the gene encoding alpha-amylase.

B. subtilis and S. cerevisiae codon usages were considered by Rare Codon Analysis software. This software shows codon adaption index (CAI), GC content and codon frequency distribution (CFD). the possibility of high level of protein expression is correlated to the value of CAI. A CAI of 1.0 is considered ideal while a CAI of $>0.8$ is rated as good for expression in the desired expression organism. The lower the number, the higher the chance that desired gene will be expressed poorly. The ideal percentage range 
of GC content is ranged from $30 \%$ to $70 \%$. Any peaks outside of this range will adversely affect transcriptional and translational efficiency. The value of 100 of CFD is set for the codon with the highest usage frequency for a given amino acid in the desired expression organism. Codons with values lower than 30 are likely to hamper the expression efficiency.

\subsection{Gene Amplification and Gel Electrophoresis}

In this study, native $B$. subtilis was used as a source of DNA for amylase gene. The amyE gene without signal peptide was amplified with forward and reverse primers that introduced AsCI and NotI restriction sites. Amplification of the amyE gene without signal sequence was performed using a Bio-Rad thermo cycler machine with the primers AmyF5'AGG CGC GCC AGT GCT GAA ACG GCG AAC AAA TCG AA 3' and 5'TTG CGG CCG CTC AAT GGG GAA GAG AAC CGC TTA AG 3'designed to incorporate AscI and NotI restriction sites to the PCR product. B. subtilis chromosomal DNA was used as template for PCR reactions. The PCR mixture consisted of $2.5 \mu \mathrm{L}$ PCR buffer, 0.5 $\mu \mathrm{L}$ dNTP mix, $1.5 \mu \mathrm{L} \mathrm{MgCl} 2$, $0.2 \mu \mathrm{LTaq}$ DNA polymerase, $1 \mu \mathrm{L}$ each of forward and reverse primers and $500 \mathrm{ng}$ of template in a total volume of $25 \mu \mathrm{L}$.

The PCR was performed with the following cycling profile: initial denaturation at $94{ }^{\circ} \mathrm{C}$ for 5 minutes, followed by 35 cycles of 1 minute denaturation at $94^{\circ} \mathrm{C}$, annealing at $54{ }^{\circ} \mathrm{C}$ for 1 minute, and extension at $72{ }^{\circ} \mathrm{C}$ for 3 minutes. The time for the final extension step was extended to 15 minutes. The PCR product was electrophoresed in $90 \mathrm{Mm}$ Tris-borate, $32 \mathrm{mM}$ EDTA on 1\% agarose horizontal slab gels. Gels were run at $80 \mathrm{~V}$, and stained with ethidium bromide for 15 minutes. The expected PCR product was purified using the BIONEER Kit.

\subsection{Cloning of the B. subtilis Alpha-amylase Gene in S. cerevisiae}

The restriction endonucleases were obtained from Fermentas (Germany) and the T4-DNA Ligase was obtained from Takara (Japan). The p316TDH3 plasmid and PCR product were double digested with AscI and NotI and gel purified using the BIONEER kit (South Korea). The PCR product was ligated to vector p316TDH3 with T4 Ligase. Ligation stage was achieved by adding T4-DNA ligase to solution containing PCR product and $\mathrm{p} 316 \mathrm{TDH} 3$ vector at $22^{\circ} \mathrm{C}$ overnight. Recombinant plasmid was transformed into E. coli competent cells. Standard cloning procedures were used and competent clones were selected by growth in the presence of ampicillin. Then, extracted plasmid DNA from the resulting clones was purified by preparation of plasmid DNA by Alkaline Lysis with SDS. The Minipreparation was done and purified recombinant plasmid was transformed into S. cerevisiae competent cells using lithium acetate and carrier sperm DNA. Recombinant yeast cells could grow on minimal media and plasmid extraction were performed from these colonies. The isolated plasmids were used to confirm the recombinant plasmid presence in yeast cells by gel electrophoresis and also used in PCR reaction as DNA template. In addition, colony PCR was performed on yeast colonies using specific amyE primers for more confidence.

\section{Results}

\subsection{Isolation of Bacilli Producing Alpha-amylase From Soil}

A simple heat treatment selective method that is efficient for the rapid isolation of soil bacilli is reported here. 11 isolated bacilli from soil, collected from five sites in Iran, showed the halo in starch medium. Biochemical tests were performed and extracted bacillus was identified. Two bacilli were known as B. subtilis, 3 bacilli as $B$. licheniformis, 1 bacillus as $B$. coagulans, 1 bacillus as $B$. polymixa and 4 bacilli as B. cereus were identified.

\subsection{Bioinformatics Analysis}

Sequence analysis with BLAST program revealed 93.65\% homology between this gene and standard alpha-amylase gene that outlined in NCB site. Results of Rare Codon Analysis showed that Codon Adaptation Index (CAI) of $B$. subtilis alpha amylase gene is 0.68 (Figure1) and the GC content is $44.72 \%$ (Figure 2). The percentage of low frequency $(<30 \%)$ codons based on our target host organism is $6 \%$ (Figure 3 ).

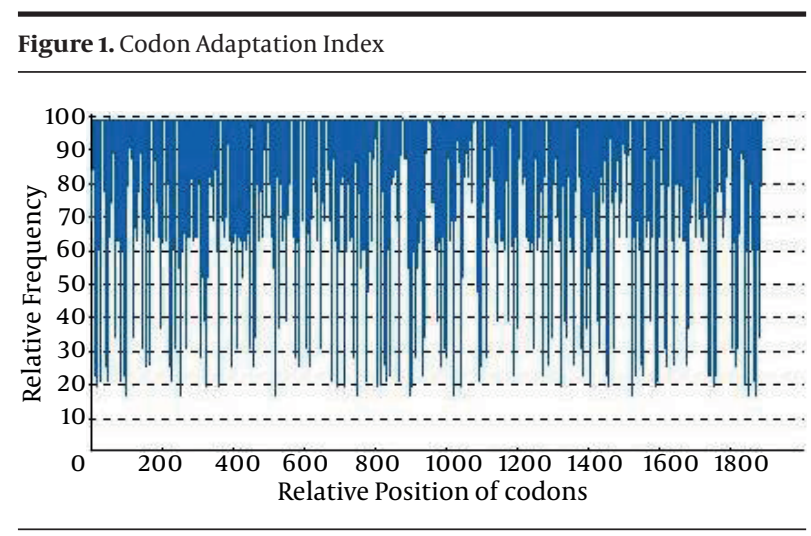

The distribution of codon usage frequency along the length of native $B$. subtilis alpha amylase gene to be expressed in S. cerevisiae. Possibility of high protein expression level is correlated to the value of CAI - a CAI of 1.0 is considered to be ideal while CAI of $>0.8$ is rated as good for expression in the desired expression organism.

The value of 100 is set for the codon with the highest usage frequency for a given amino acid in the desired expression organism. Codons with values lower than 
30 are likely to worsen the expression efficiency.

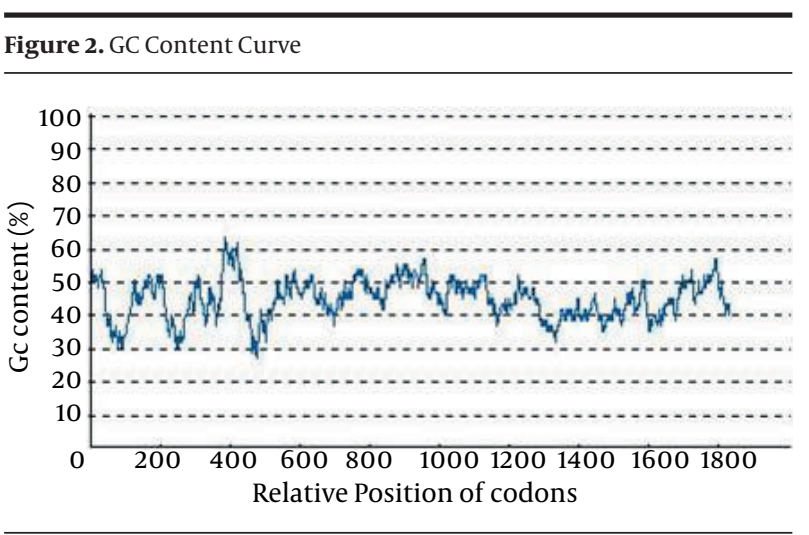

The ideal percentage range of GC content is between 30\% to 70\%. Any peaks outside of this range will adversely affect the transcriptional and translational efficiency.

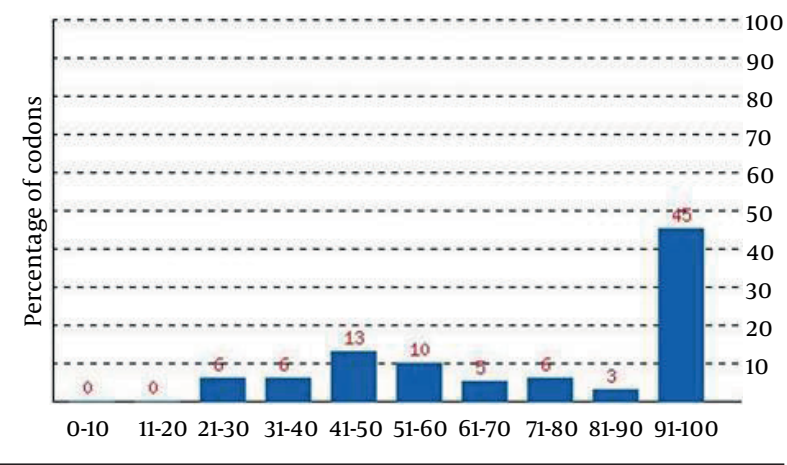

Figure 3. The Percentage of Codon Distribution in Computed Codon Quality Groups

\subsection{Gene Amplification and Sequencing}

The PCR amplification of the alpha-amylase gene resulted in production of a band in the expected region of 1887 bp as shown in Figures 4.

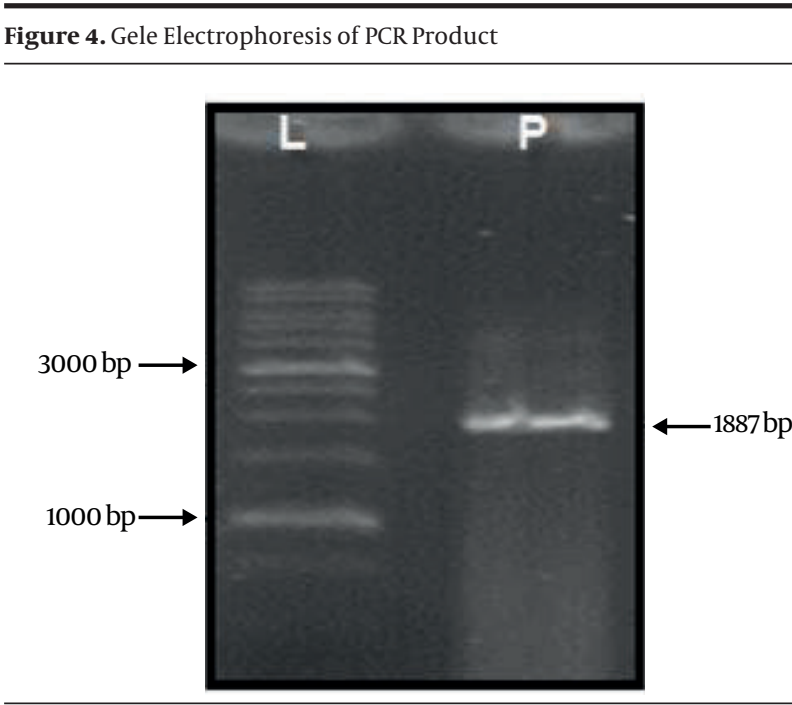

\section{L: 1 kb ladder. P: PCR product}

Figure 5. Digestion of Plasmid and PCR Product With NotI and AscI Restriction Enzymes

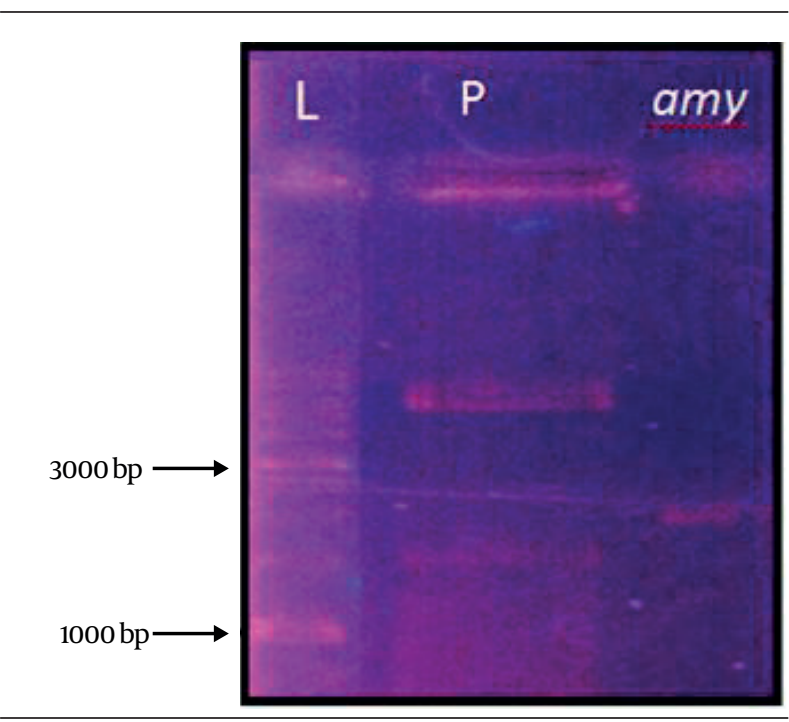

L: 1 kb ladder. P: plasmid. Amy: alpha amylase gene.

4.4. Cloning of the B. subtilis Alpha- amylase Gene in E. coli and S. cerevisiae

Transformation of recombinant p316TDH3 plasmid in E. coli $\mathrm{DH} 5 \alpha$ produced several colonies containing the recombinant plasmid. The colonies of E. coli carrying recombinant plasmid were tested by colony-PCR that confirmed the presence of alpha-amylase gene (Figure 6).

Figure 6. Colony-PCR Recombinant E. coli

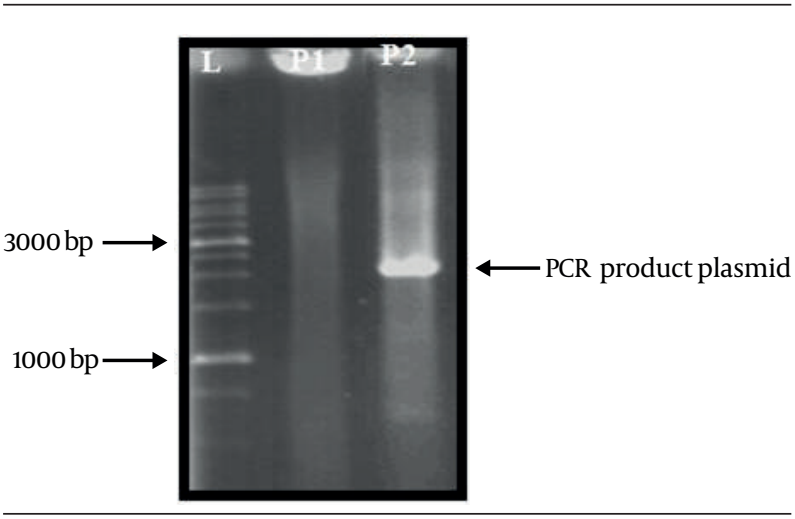

L: 1 kb ladder. P1: PCR product of non-recombinant strain. P1. PCR product of recombinant strain.

Recombinant plasmid was extracted (Figure 7), and cloned into S. cerevisiae. Transformed cells were grown in minimal medium. Recombinant cells grown in minimal medium were tested by colony-PCR with 
specific primers.

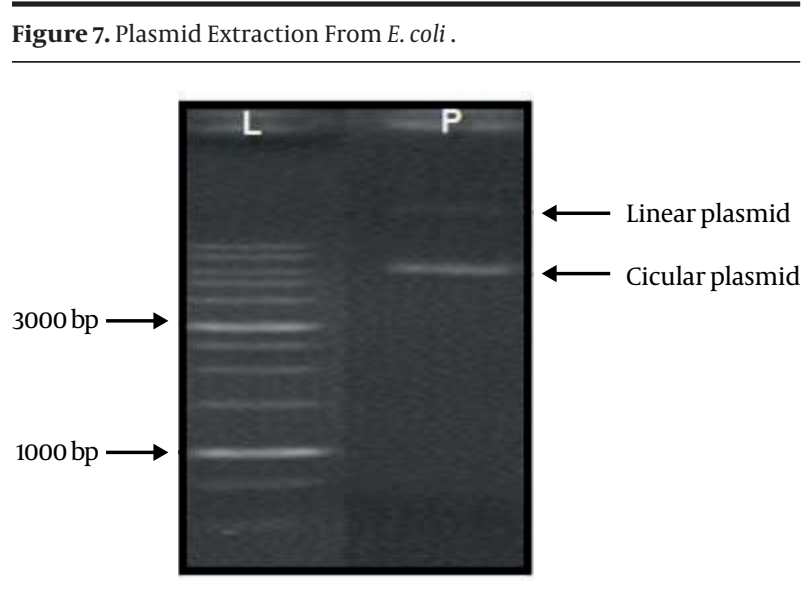

L:1 kb ladder. P: Linear and circular plasmid bands.

\section{Discussion}

The aim of the current research project was to isolate amylase gene from Iranian native $B$. subtilis strain and to clone into $S$. cerevisiae. Bacillus species are among bacteria that are widely used for production of commercial enzymes, so bacilli producing alpha-amylase were extracted from different soils in Iran that are identified by chemical test. Results showed two extracted bacilli were B. subtilis and produced alpha-amylase well. In same study to identify bacterial strain producing alpha-amylase, 72 single bacterial colonies, which produced clear halos with iodine solution were selected and purified. Among these strains, B. licheniformis alpha-amylase showed the highest activity (22).

The homology results revealed significant similarity between native $B$. subtilis alpha-amylase and alpha-amylase from B. subtilis 186 (93.65\% similarity). The phylogenetic relationship analysis indicated that native $B$. subtilis alpha-amylase is genetically closely related to $B$. subtilis amylase, which belong to the glycosyl hydrolase family 13 (23). Therefore, this gene should be classified as a member of glycosyl hydrolase family 13. So this result confirms the results of biochemical tests to identify bacilli extracted from different soils. The deduced amino acid sequence of the mature enzyme was compared with those of other a-amylases obtained from Bacilli strains. Four highly conserved regions among amylolytic enzymes designated I, II, III and IV were found in the deduced amino acid sequence of native B. subtilis. This protein shares $89.18 \%$ identity with the sequence of the reference standard $B$. subtilis. These enzymes differ by 68 amino acids.

The possibility of high protein expression level is correlated with the value of CAI. CAI of 1.0 is considered ideal while a CAI of $>0.8$ is known as good expression level in the desired expression organism. The lower the number, the higher the chance that desired gene will be expressed poorly. The ideal percentage of GC content is ranged from $30 \%$ to $70 \%$. Any peaks outside of this range will adversely affect transcriptional and translational efficiency. The value of 100 of CFD is set for the codon with the highest usage frequency for a given amino acid in the desired expression organism. Codons with values less than 30 are likely to have ill effects on the expression.

Also computation GC content of the gene encoding alpha amylase from native $B$. subtilis is $44.44 \%$. It seems that the GC content of this gene could be influenced by the GC content of the total nuclear DNA that is $43.5 \%$ and also has similarity with the GC content of $S$. cerevisiae (24). The GC content of $S$. cerevisiae is $38 \%$. The similarity of GC content between cloned gene and host is very important for high efficiency expression. Also result of Rare Codon Analysis software showed Codon Adaptation Index (CAI) of this gene is 0.68 that is less than the optimum value. The percentage of low frequency $(<30 \%)$ codons based on S. cerevisiae host is $6 \%$. This un-optimized gene employs tandem rare codons that can reduce the efficiency of translation or even disengage the translational mechanisms (25). But these results show that amyE gene can be expressed in $S$. cerevisiae.

In attention to these results and results obtained from working on cloning of alpha-amylase gene from B. subtilis PY22 in Pichiapastoris and B. stearothermophilus in S. cerevisiae can be understood the gene encoding alpha-amylase from native B. subtilis can express in S. cerevisiae as host $(11,26)$. The presenting of alpha-amylase gene in recombinant colonies was tested with colony-PCR method. After extracting recombinant plasmid from E. coli, it was cloned into S. cerevisiae. The Vector p316tdh3 has biosynthetic marker URA3. Genetic markers are an indispensable component of modern molecular cloning strategies, because they facilitate the high-efficiency screening of target-trans formants. The two most widely used genetic markers are antibiotic resistance marker and biosynthetic marker (27).

Among these, antibiotic resistance markers are widely applied in the genetic manipulation of yeast (28). However, there are several limitations to the application of antibiotic resistance markers in eukaryote microorganisms: 1-high price and instability; 2 - high level of maximum tolerance concentrations; 3- high amount of false-positive ratios (28); 4- the natural tolerance by some yeast strains to many common antibiotics (29); 5- possible effects on the physiological function of yeast by introduction of antibiotic resistance markers (30); and 6- in some cases, failure of a specific system, like the genetic operation of mitochondrial genome (30). The URA3 and LEU2 genes are common biosynthetic markers for yeast strains and do not present the above mentioned disadvantages (31). The rapidly increased use of yeast in industrial biotechnology requires elucidation of the physiological characteristics and subsequent genetic operation of the yeast strains by molecular cloning techniques. This has resulted in a high 
demand for auxotrophic strains such as $\Delta$ ura3, $\Delta$ leu2 or $\Delta$ his4 mutants (32). The strain used in this project was $\Delta$ ura3. So the extracted plasmid was cloned in S. cerevisiae $\Delta$ uraz by lithium acetate method.

The first methods for the transformation of S. cerevisiae involved enzymatic removal of the cell wall to produce sphaeroplasts which is time-consuming approach. A more convenient method was later developed in which intact yeast cells were made competent by treatment with lithium ions. This method is now widely used despite the fact that it gives lower frequencies; a variation using DMSO increases frequency 25-fold. More recently a third approach, electroporation, is very fast and high efficiency. Since the lithium acetate method is a rapid and easy approach, it is used commonly (33). So we choose this method in this study. Recombinant $S$. cerevisiae was grown on minimal medium and was tested by colonyPCR to confirm the presentation of alpha amylase gene. In some studies, formation of halo in starch medium has used to indicate the existence of gene in recombinant strains $(34,35)$.

Utilization of low-value agro-industrial residues as substrates should be focused for enzyme production, as this would reduce the cost of production and help to solve the pollution concerns. In attention to the fact that for drugs with limited solubility or in some drugs which solubility can be influenced by variation on gastro-intestinal $\mathrm{pH}$, a system is required to accelerate the drug release and polysaccharide biodegradable matrices are of interest, since the degradation of a natural products such as starch occurs naturally in the human body, it is hoped that amylases will continue to provide new opportunities in biotechnology as biocatalysts and that new applications will emerge in the biopharmaceutical sectors. Also in order to use alpha-amylase in different industries, it can be focused on the enzyme production with various features. This enzyme can be produced by site- direct mutagenesis on desired genes and or synthesis of these genes.

\section{Acknowledgements}

We express our thanks to the post-graduation office of Shahrekord University for financial supports in this research project.

\section{Authors' Contribution}

None declared.

\section{Financial Disclosure}

None declared.

\section{Funding/Support}

None declared.

\section{References}

1. Calik P, Ozdamar TH. Carbon sources affect metabolic capacities of Bacillus species for the production of industrial enzymes: theoretical analyses for serine and neutral proteases and alphaamylase. Biochem Eng J. 2001;8(1):61-81.

2. Pandey A, Nigam P, Soccol CR, Soccol VT, Singh D, Mohan R. Advances in microbial amylases. Biotechnol Appl Biochem. 2000;31 ( Pt 2):135-52.

3. Ibrahim CO. Development of applications of industrial enzymes from Malaysian indigenous microbial sources. Bioresour Technol. 2008;99(11):4572-82.

4. Sumitani J, Hattori N, Nakamura Y, Okuda Y, Kawaguchi T, Arai $\mathrm{M}$. The conserved tryptophan-arginine-tyrosine motif of a proteinaceous alpha-amylase inhibitor T-76 from Streptomyces nitrosporeus is important for inhibition of animal alpha-amylases but not for an alpha-amylase from Bacillus sp. no. 195. J Biosci Bioeng. 2000;90(1):74-80.

5. Lonsane BK, Ramesh MV. Production of bacterial thermostable alpha-amylase by solid-state fermentation: a potential tool for achieving economy in enzyme production and starch hydrolysis. Adv Appl Microbiol. 1990;35:1-56.

6. Kathiresan K, Manivannan S. Alpha- amylase production by Penicillium fellutanum isolated from mangrove rhizosphere soil. African J Biotechnol. 2006;5(10).

7. Vieille C, Zeikus GJ. Hyperthermophilic enzymes: sources, uses, and molecular mechanisms for thermostability. Microbiol Mol Biol Rev. 2001;65(1):1-43.

8. Schallmey M, Singh A, Ward OP. Developments in the use of Bacillus species for industrial production. Can J Microbiol. 2004;50(1):1-17.

9. Asgher M, Asad MJavaid, Rahman SU, Legge RL. A thermostable $\alpha$-amylase from a moderately thermophilic Bacillus subtilis strain for starch processing. J Food Engin. 2007;79(3):950-955.

10. Declerck Nathalie, Machius Mischa, Joyet Philippe, Wiegand Georg, Huber Robert, Gaillardin Claude. Engineering the thermostability of Bacillus licheniformis alpha-amylase. BiologivaBratislava . 2002;57(SUP/2):203-212.

11. Karakaș Barçın, İnan Mehmet, Certel Muharrem. Expression and characterization of Bacillus subtilis PY22 $\alpha$-amylase in Pichia pastoris. J Mol Cat B: Enzymatic. 2010;64(3-4):129-134.

12. Niu D, Shi G, Wang Z. Genetic improvement of alpha-amylase producing Bacillus licheniformis by homolog-mediated alphaamylase gene amplification. Sheng Wu Gong Cheng Xue Bao. 2009;25(3):375-80.

13. Dujon B. The yeast genome project: what did we learn? Trends Genet. 1996;12(7):263-70.

14. Curran Brendan PG, Bugeja Virginia C. Yeast cloning and biotechnology 1993;155-175.

15. Hicks JB, Hinnen A, Fink GR. Properties of yeast transformation Cold Spring Harb Symp Quant Biol. 1979;43 Pt 2:1305-13.

16. Iefuji H, Chino M, Kato M, Iimura Y. Raw-starch-digesting and thermostable alpha-amylase from the yeast Cryptococcus sp. S-2: purification, characterization, cloning and sequencing. Biochem J.1996;318 ( Pt 3):989-96.

17. Xu D, Yan X. Molecular cloning and characterization of an alphaamylase with raw starch digestibility from Bacillus sp. Annals Microbiol. 2009;59:91-96.

18. Brayer GD, Luo Y, Withers SG. The structure of human pancreatic alpha-amylase at 1.8 A resolution and comparisons with related enzymes. Protein Sci.1995;4(9):1730-42.

19. Svensson B. Protein engineering in the alpha-amylase family: catalytic mechanism, substrate specificity, and stability. Plant Mol Biol. 1994;25(2):141-57.

20. Hamilton Lynn M, Kelly Catherine T, Fogarty William M. Purification and properties of the raw starch-degrading $\alpha$-amylase of Bacillus sp. IMD 434. Biotechnol Lett. 1999;21(2):111-115.

21. Vihinen M, Mantsala P. Microbial amylolytic enzymes. Crit Rev Biochem Mol Biol.1989;24(4):329-418.

22. Vasseekaran S, Balakumar S, Arasaratnam V. Isolation and Identification of a Bacterial Strain Producing Thermostable alphaamylase. Tropl Agri Res. 2012;22:1-11.

23. van der Maarel MJ, van der Veen B, Uitdehaag JC, Leemhuis H, Di jkhuizen L. Properties and applications of starch-converting en- 
zymes of the alpha-amylase family. J Biotechnol. 2002;94(2):13755.

24. Westers H, Dorenbos R, van Dijl JM, Kabel J, Flanagan T, Devine $\mathrm{KM}$, et al. Genome engineering reveals large dispensable regions in Bacillus subtilis. Mol Biol Evol. 2003;20(12):2076-90.

25. Rosano GL, Ceccarelli EA. Rare codon content affects the solubility of recombinant proteins in a codon bias-adjusted Escherichia coli strain. Microb Cell Fact. 2009;8:41.

26. de Moraes Lidia MP, Astolfi Filho Spartaco, Ulhoa Cirano J. Purification and some properties of an $\alpha$-amylase glucoamylase fusion protein from Saccharomyces cerevisiae. World Microbiol Biotechnol. 1999;15(5):561-564.

27. Adrio JL, Demain AL. Genetic improvement of processes yielding microbial products. FEMS Microbiol Rev. 2006;30(2):187-214.

28. Alderton AJ, Burr I, Muhlschlegel FA, Tuite MF. Zeocin resistance as a dominant selective marker for transformation and targeted gene deletions in Candida glabrata. Mycoses. 2006;49(6):445-51.

29. Prasad R, Kapoor K. Multidrug resistance in yeast Candida. Int Rev Cytol. 2005;242:215-48.
30. Rak M, Tetaud E, Godard F, Sagot I, Salin B, Duvezin-Caubet S, et al. Yeast cells lacking the mitochondrial gene encoding the ATP synthase subunit 6 exhibit a selective loss of complex IV and unusual mitochondrial morphology. J Biol Chem. 2007;282(15):10853-64.

31. Vemuri GN, Eiteman MA, McEwen JE, Olsson L, Nielsen J. Increasing NADH oxidation reduces overflow metabolism in Saccharomyces cerevisiae. Proc Natl Acad Sci U S A. 2007;104(7):2402-7.

32. Wang TT, Choi YJ, Lee BH. Transformation systems of non-Saccharomyces yeasts. Crit Rev Biotechnol. 2001;21(3):177-218.

33. Wu S, Letchworth GJ. High efficiency transformation by electroporation of Pichia pastoris pretreated with lithium acetate and dithiothreitol. Biotechniques. 2004;36(1):152-4.

34. Shiosaki K, Takata K, Omichi K, Tomita N, Horii A, Ogawa M, et al. Identification of a novel alpha-amylase by expression of a newly cloned human amy3 cDNA in yeast. Gene.1990;89(2):253-8.

35. Yin XH, Gagnat J, Gerbaud C, Guerineau M, Virolle MJ. Cloning and characterization of a new alpha-amylase gene from Streptomyces lividans TK24. Gene. 1997;197(1-2):37-45. 